\title{
Comparative analysis of transcrptome profiling to identify genes involved in bulged surface of pear fruits (Pyrus bretschneideri Rehd. cv. Yuluxiangli)
}

\section{Baopeng Ding}

Shanxi Agricultural University

Chaohui Hu

Shanxi Agricultural University

\section{Yuqin Song}

Shanxi Agricultural University

\section{Ruijie Hao}

Shanxi Agricultural University

\section{Xinxin Feng}

Shanxi Agricultural University

\section{Tingting Cui}

Shanxi Agricultural University

Liulin Li ( $\nabla$ sxaulll@sxau.edu.cn )

Shanxi Agricultural University

\section{Research article}

Keywords: Pear (Pyrus); bulged surface; paclobutrazol; auxin; DEGs

Posted Date: May 1st, 2020

DOl: https://doi.org/10.21203/rs.3.rs-22697/v1

License: (9) This work is licensed under a Creative Commons Attribution 4.0 International License. Read Full License 


\section{Abstract}

Background: Pear (Pyrus spp.) belongs to the genus Pyrus, in the family Rosaceae. Some varieties of pear fruits exhibit bulged surface, which seriously affect the quality and commodity value. In this study, we performed anatomical, physiological and transcriptomic analysis, to explore the mechanism of paclobutrazol (PBZ) on the bulged surface of pear fruits.

Results: The vascular bundles of flesh were more evenly distributed and the cells arranged more compactly with smaller size. However, the auxin (IAA) content of flesh decreased significantly when treated with PBZ. Further, the GO and KEGG analysis of differentially expressed genes (DEGs) showed that auxin, phenylpropanoid metabolic pathways and transcriptional factor genes were significantly enriched on the relieved bulged surface of pear fruits. The promoter region analysis of selected DEGs showed that some genes contained auxin responded cis-elements.

Conclusion: We conclude that PBZ might play a negative role in the cell division, cell elongation and vascular bundle development on bulged surface of pear fruits through the involvement of auxin related genes. This study will provide theoretical basis for the regulation of bulged surface of pear fruits by growth retardant agent.

\section{Background}

The pear tree is a specie of genus Pyrus in the family Rosaceae, bearing the pomaceous fruit of the same name, which is the third largest temperate fruit tree and widely cultivated in the world [1,2]. However, some high-quality cultivated species, such as 'Korla' fragrant pear (Pyrus sinkiangensis Yu) and its bred variety 'Yuluxiangli' (Pyrus bretschneideri Rehd.), have the phenomenon of bulged surface fruits, which results in low-quality of fresh pear fruits with poor appearance and affects their value of commodity [3].

Plant growth retardants, negatively regulate plant growth and development by inhibiting hormones and help in partitioning of assimilates effectively [4-6]. Spraying growth retardants, such as paclobutrazol (PBZ), a member of the triazole family, at full bloom stage could significantly relieve bulged surface of pear fruits and improve its appearance [3]. It was reported that PBZ inhibited IAA and other hormones effects to delay growth vigor [7]. Therefore, the unbalanced distribution of endogenous hormones, might lead to uneven growth of various parts of the fruits, which might be one of the key factors leading to bulged surface of fruits. Previously, It was showed that the vascular bundles at the calyx end of young fruit were significantly retarded in pear by growth retardant PBZ $[8,9]$. Vascular tissues were responsible for the transport of water, nutrients and photosynthetic products during plant growth and development [10-12]. Thus, we speculated that the growth and development of vascular bundles might directly affect the bulged surface of pear fruits. Furthermore, PBZ caused palisade and spongy leaves with more compact cell arrangement and smaller cell size $[13,14]$.

IAA plays an important role in vascular development through the auxin carrier, such as pin-formed 1 (PIN1), auxin efflux carrier, which affects the development of vascular bundles [15-17]. Some previous 
studies showed that auxin influx carrier LAX2 was involved in vascular bundle development $[18,19]$. Does PBZ affect the growth and development of vascular bundles by negatively regulating auxin and retarding strong growth vigor, thus relieving the bulged surface in pear fruits?

Lignin is distributed in cell walls of lignogenic vascular machinery, rigidifying them and rendering them impermeable to water. Thus, lignin plays important roles in increasing the strength of the cell wall and enhancing the ability of water transport in plants [20]. In lignin biosynthesis process, some genes such as F5H (ferulic acid-5-hydroxylase), 4CL (4-coumaric acid COA ligase) and COMT (caffeic acid/5hydroxyferulic acid-O-methyltransferase) genes could also affect the growth and development of vascular tissue [21-23]. In addition, bHLH transcription factor, such as target of monoperos 5 (tmo5) interacted directly with ARF (auxin responsive gene), and playing a significant role in the procambium tissue, where the vascular bundles split and bHLH interacted directly with another bHLH transcriptional factor LHW to act on ARF5/MP $[24,25]$. Some other transcriptional factors, such as MYB, were also found to be involved in the accumulation of lignin, during vascular bundle growth and development [2628]. Are these genes related to vascular development involved in pear-bulged surface and regulated by PBZ?

'Yuluxiangli' is a Chinese cultivated pear variety, famous for its high production and good quality fruits. However, producing bulged surface fruits is one of the major problems, facing this variety. Recently, researches were performed to investigate the cause of its bulge surface fruits and find out the prevention measures $[3,29]$. However, the molecular mechanism of pear fruits bulged surface is still unclear. For this reason, in our study, the plant of full blooming flower of 'Yuluxiangli' was treated with the growth retarding agent PBZ, to explore the causing factors of the bulged surface of fruits, from structural, physiological and transcriptomic data. This study will provide theoretical as well as molecular basis for the regulation of bulged surface of pear fruits by growth retardant agent.

\section{Results}

\section{The morphological and anatomical features of bulged surface of pear fruits}

PBZ plant growth retardant was sprayed at the full blooming stage of 'Yuluxiangli', then fruit samples were collected after 85 days of plants full blooming stage. The surface of fruits in the control group were significantly bulged (Fig. 1a and 1b, CK; Additional file Fig. S1), whereas the fruits with smooth surface and diagonally round shape were treated with PBZ (PK)(Fig. 1a and 1b). Further, 10.8 and 6 number of vascular bundles were observed and sprayed with $\mathrm{ddH}_{2} \mathrm{O}$ (CK) and PBZ (PK), respectively (Fig. 1c). Moreover, the result showed that the cross section of fruits vascular bundles were dense and irregular in shape of the control group, when sprayed with water; whereas the vascular bundles were distributed uniformly and developed gradually and its shape was round, when treated by growth retardant agent PBZ (Fig. 1d). 


\section{The content of IAA in relieved bulge surface of pear fruits}

The IAA content of pear fruits was $24.86 \mathrm{ng} / \mathrm{g}$ in control group. But when treated with PBZ it was $18.27 \mathrm{ng} / \mathrm{g}$ (Fig. 2). The IAA content was higher in CK group than that of treated group (PK).

\section{The paraffin section and its characteristic of bulged surface of fruits}

The result of paraffin wax sections showed that the cells were sparse and irregular in control group of fruits, however the result of the cells of fruits were round and smaller in size, with more compaction observed when treated by PBZ (Fig. 3a). Furthermore, the number of cells was 9.27 and $20.53 / 100 \mu \mathrm{m} \times$ $100 \mu \mathrm{m}$ in CK and PK groups, respectively (Fig. 3d); the number of cell layers was 9.67 and $15.40 / 400$ $\mu \mathrm{m} \times 400 \mu \mathrm{m}$ in CK and PK groups, respectively (Fig. 3c). And the length of fruit cell was $70.64 \mu \mathrm{m}$ and $12.27 \mu \mathrm{m}$ in CK and PK groups, respectively (Fig. 3b). The paraffin wax section showed that the length of fruit cells in control group was significantly longer than that of treated by PBZ. Further, the elongated and morphological irregular cell sizes were observed in control group. And the number of cells and cell layers were significantly reduced in control group.

\section{Identification genes involved in bulged surface of pear fruits}

Sequencing of samples was the same as 2.1. A total of 442 differentially expressed genes (DEGs) were identified in this study, of which 249 were up-regulated and 193 were down-regulated in response to growth retardant agent PBZ (Additional file Fig. S2 and Additional file Table S1).

All DEGs were annotated by blasting their sequences against eight publically available databases such as COG, GO, KEGG, KOG, NR, Pfam, Swiss-prot and eggNOG. Significant annotation matches were found for 440 DEGs (99.5\%) in all databases (Additional file Table S2 and Additional file Table S3).

In order to explore the relationship of expressed genes, involved in the function of regulating bulged surface of fruits, we determined the important biological functions of 442 DEGs by GO and KEGG analysis. The selected up- and down-regulated DEGs were assigned to two main GO categories: molecular function and biological process, significantly enriched in phenylpropanic metabolic pathway, which were related to the lignin biosynthesis of vascular bundle. The selected DEGs of the molecular function were further distributed into four different groups, namely, trans-cinnamate 4-monooxygenase activity (G0:0016710, Pbr013141), electronic carrier activity (GO:0009055, Pbr040547 and Pbr013141), iron ion binding (G0:0005506, Pbr040547, Pbr013141), DNA binding (G0:0003677, Pbr035111, Pbr013141), sequence specific DNA-binding transcription factor activity (G0:0003700, Pbr007589); whereas the selected DEGs of the biological process were attributed into two groups, which were related to the metabolic process (GO:0008152, Pbr012851) and the oxidation reduction process (G0:0055114, Pbr024635, Pbr013141 and Pbr040547) (Fig. 4a and Additional file Table S4). 
To further study the biological pathways of DEGs triggered by growth retardant agent PBZ, they were annotated by blast analysis against the KEGG database. PBZ treatment relieved the bulged surface of pear fruits, through highly complex biological processes. However, the three important pathways namely, plant hormones (Ko04075), phenylpropane (Ko00940) and phenylalanine pathway (Ko00360) were significantly involved in the vascular bundle growth and development (Additional file Table S5). KEGG metabolic pathway analysis showed that six DEGs were involved in hormone signaling pathway. For example auxin efflux carrier genes (PIN, k13947, Pbr028379, Pbr038852), auxin responsive genes (GH3, k14487, Pbr030587, Pbr030571 and Pbr021158) and auxin influx carrier genes (LAX, ko04075, Pbr009498). However, only GH3 and PIN gene expression were up-regulated, but the other auxin-related genes were down-regulated in the fruit in response to PBZ. Seven DEGs related to phenylpropanic biosynthesis were down-regulated in pear flesh treated by PBZ reagent, including ferulic acid-5hydroxylase (F5H, k09755, Pbr040547) [EC:1.14.], caffeic acid 3-O-methyltransferase (COMT, k13066, Pbr013510) [EC:2.1.1.68], peroxidase (PRX, k04430, Pbr031894) [EC:1.111.7], caffeinyl shikimate esterase (CAE, k18368, Pbr002415) [EC:3.1.1-], 4-coumaric acid coenzyme ligase (4CL, k01904, Pbr024635, Pbr012851) [EC:6.2.1.12] and trans-cinnamic acid 4-monooxygenase (CYP73A2, k00487, Pbr013141) [EC:1.14.13.11]. And four genes, which were also involved in the phenylpropane pathway, participated in flavonoid synthesis (Ko00941, Pbr013141), stilbenid, dialheptanoid and ginger biosynthesis (Ko00945, Pbr013141), ubiquinone and other terpenoid quinone biosynthesis (Ko00130, Pbr012851, Pbr013141 and Pbr024635) and phenylalanine metabolism (Ko00360, Pbr012851, Pbr013141 and Pbr024635) (Fig. 4b, Table 1 and Additional file Table 5). Meanwhile, the expression of cellulose synthesis DEGs (CesA, k10999, Pbr038537, Pbr034219) [EC:2.4.1.12] were down-regulated in response to PBZ (Fig. 4c and Table 1). Further we found some transcriptional factor genes from 442 DEGs, such as, bHLH130 (Pbr032736), bHLH93 (Pbr001646), MYBS3 (Pbr015587), NAC002 (Pbr020642) and DOF4.6 (Pbr035111), which were down-regulated in response to PBZ (Fig. 4c and Additional file Table S6).

The selected expression profile of DEGs, which might be involved in bulged surface of pear fruits, were analyzed and the candidate DEGs with similar expression patterns were clustered together based on their up- and down-regulated nature (Fig. 4c and Additional file Table S6). 
Table 1

Cis-acting elements identified from the promoter regions of candidate genes.

\begin{tabular}{|c|c|c|c|c|}
\hline $\begin{array}{l}\text { Gene } \\
\text { name }\end{array}$ & $\begin{array}{l}\text { Cis- } \\
\text { element }\end{array}$ & Sequence & Species & Function \\
\hline Pbr001646 & $\begin{array}{l}\text { AuxRR- } \\
\text { core }\end{array}$ & GGTCCAT & $\begin{array}{l}\text { Nicotiana } \\
\text { tabacum }\end{array}$ & $\begin{array}{l}\text { cis-acting regulatory element involved in } \\
\text { auxin responsiveness }\end{array}$ \\
\hline Pbr013141 & $\begin{array}{l}\text { AuxRR- } \\
\text { core }\end{array}$ & GGTCCAT & $\begin{array}{l}\text { Nicotiana } \\
\text { tabacum }\end{array}$ & $\begin{array}{l}\text { cis-acting regulatory element involved in } \\
\text { auxin responsiveness }\end{array}$ \\
\hline Pbr013510 & AuxRE & TGTCTCAATAAG & $\begin{array}{l}\text { Glycine } \\
\max \end{array}$ & part of an auxin-responsive element \\
\hline Pbr024913 & $\begin{array}{l}\text { AuxRR- } \\
\text { core }\end{array}$ & GGTCCAT & $\begin{array}{l}\text { Nicotiana } \\
\text { tabacum }\end{array}$ & $\begin{array}{l}\text { cis-acting regulatory element involved in } \\
\text { auxin responsiveness }\end{array}$ \\
\hline Pbr030571 & $\begin{array}{l}\text { AuxRR- } \\
\text { core }\end{array}$ & GGTCCAT & $\begin{array}{l}\text { Nicotiana } \\
\text { tabacum }\end{array}$ & $\begin{array}{l}\text { cis-acting regulatory element involved in } \\
\text { auxin responsiveness }\end{array}$ \\
\hline Pbr034219 & $\begin{array}{l}\text { AuxRR- } \\
\text { core }\end{array}$ & GGTCCAT & $\begin{array}{l}\text { Nicotiana } \\
\text { tabacum }\end{array}$ & $\begin{array}{l}\text { cis-acting regulatory element involved in } \\
\text { auxin responsiveness }\end{array}$ \\
\hline \multicolumn{5}{|c|}{ Supplementary Materials } \\
\hline
\end{tabular}

\section{Predication of cis-regulatory elements and their distribution in candidate genes caused the bulged surface of pear fruits}

To better understand transcriptional regulation of the candidate genes (Additional file Table S6), the cisacting elements located in the 1.5-kb regions upstream of their start codons (ATG) were predicted by searching against the PlantCare online tool. The results showed that, the six genes (Pbr001646, Pbr013141, Pbr013510, Pbr024913, Pbr030571 and Pbr034219) contained auxin responsive cisregulatory elements AuxRR-core (GGTCCAT) or AuxRE (TGTCTCAATAAG) (Table 1). This indicated that auxin might involve in regulating bulged surface of pear fruits.

\section{Validation of DEGs by real-time qRT-PCR analysis}

To validate the RNA-seq data, we randomly selected nine DEGs namely; PIN, LAX1, CYP73A2, COMT, CesA, $b H L H, M Y B, G H 3.1$ and GH3.6 for qRT-PCR analysis in pear fruits in response to PBZ treatment. Transcriptional levels of these six genes by qRT-PCR showed that ( $L A X 1, C Y P 73 A 2, C O M T, C e s A, b H L H$, $M Y B$ ), involved in plant hormone transporting, phenylpropionic acid pathway, cellulose pathway and plant transcription, were significantly down-regulated in response to PBZ treatment, however only $\mathrm{GH} 3$ and PIN genes were up-regulated compared with the control group (Fig. 5). Similar patterns of genes expression were observed between the qRT-PCR and RNA-seq-generated data. 


\section{Discussion}

It had been reported that the bulged surface of fruits could be significantly improved through cultivation measures and exogenous spraying of growth retardant agent [3]. However, the research on mechanism is still unknown. In this study, we explored the mechanism of growth retardant agent (PBZ) relieving bulged surface by means of histomorphology, exogenous hormones and transcriptome analysis.

\section{PBZ retarded the growth and development of cell and vascular bundles}

Schematic analysis revealed that the surface of pear fruit and their vascular bundles were unevenly distributed in the bulge part of the fruits in the control group (CK). But it was evenly distributed in the transverse direction in fruits treated with growth retardant PBZ (PK)(Fig. 1, Additional file Fig. S1). It was previously reported that the developed vascular bundles were densely distributed at the calyx end of the bulged surface of pear fruits. However, these vascular bundles were developed slowly and distributed loosely at the calyx end of fruits in PBZ treated group [4,5]. And phloem cells appeared to become much smaller and tighter treated by PBZ than that of CK group [6]. These findings suggest that PBZ might affect the growth and development of the vascular bundles in the fruits, thus affecting the bulge shape on the surface fruits.

The cells were well division and development in CK group. And the length of cell became long in CK group (Fig. 3a). Furthermore, the control group showed that the cell arrangement was relatively wobbly, the cell sizes and layers were significantly increased in the course of making paraffin wax section. Whereas the cells in the transverse section near the fruit pericarps, treated with growth retardant PBZ, were found compact, small and arranged; and cell layer increased in PK group (Fig. 3b-3d). Researchers showed that palisade and spongy cells became smaller when sprayed with PBZ [6]. Meanwhile,the ratio of palisade to sponge layer thickness was increased[7,31], but cell longitudinal growth was inhibited in PBZ group [3032]. Our data, together with previously reported studies, suggested that the growth retardant agent (PBZ) could affect cell size,cell layer arrangement and inhibit cell longitudinal growth.

\section{PBZ reduced the content of IAA bulged sruface of fruits}

Auxin is one of the important endogenous hormones, which plays an essential role in many processes of plant growth and development, such as promoting cell division and elongation [33-35] and vascular tissue formation and differentiation [36-38]. Our observation of auxin results indicated that IAA content was dropped in fruits treated by PBZ compared with CK group (Fig. 2). Our results were consistent with previous studies showing that IAA content was reduced in plant tissue treated by PBZ [11-13]. In addition, the result further showed that bulged surface fruits caused by strong growing vigor contained with high IAA and was relieved by the way of balancing phytohormone, especially IAA, among tissues. 


\section{PBZ degraded the expression of auxin and lignin related genes}

GO and KEGG analysis revealed that auxin transport-related genes $L A X$ were down-regulated and auxin responded GH3 genes and auxin efflux carrier (PIM) genes were up-regulated in pear fruits treated by PBZ. In addition, we found that lignin synthesis genes CYP73A2, COMT and cellulose synthesis genes involved in construction of vascular bundle were found down-regulated in the pear fruits treated by PBZ.

Meanwhile, transcriptional factor genes such as $b H L H$ and $M Y B$ were down-regulated in PBZ treated pear fruits (Fig. 5). Real Time qRT-PCR analysis of these differentially expressed genes were consistent with that of RNA-seq data, which confirmed the reliability of the experimental data. Previous reports showed that auxin affected vascular bundle formation through auxin efflux carrier PIN $[16,39,40]$. Auxin efflux carrier genes were highly expressed in mutant vascular bundles $[15,40,41]$. Similar studies were reported that auxin influx carrier LAX supported vascular bundle development $[18,42]$. In addition, the active state of IAA was inactivated by $G H 3$ genes $[26,43]$. Further our results proved that the PBZ treatment might change the auxin pathway genes activity to reduce IAA content, and could affect the distribution of transverse vascular bundles, cell division and cell elongation on the surface fruits, thus regulating the bulged surface in pear fruits.

In addition, it had been reported that, phytohormones, lignin synthesis related genes such as phenylpropane metabolic pathway genes CYP73A2 and COMT [44,21,22], transcriptional factor genes $b H L H$ and $M Y B$, as well as cellulose synthetase genes were involved in vascular tissue, growth, development and metabolism of its secondary cell wall. On the other hand, $b H L H$ genes played an important role in early vascular bundle development $[45,46]$. MYBs, directly act on VND6 and VND7, which were involved in the formation of vessel and xylem of secondary cell walls $[47-49,27,50]$. Furthermore, overexpression of MYB52 and MYB54 up-regulates cellulose synthase 8 (CesA8) activity [51,52] and 4coumarate-CoA ligase $(4 C L)[53,54]$ in cellulose and lignin synthesis. Some of the above differentially expressed genes showed that there were six genes which responds to auxin. These results indicated that PBZ treatment might affect vascular bundle development by changing the genes in response to auxin (Fig. 2 and Additional file Table S5).

In a word, this research presented a comprehensive overview of PBZ, which might regulate genes function involved in auxin metabolic pathway. Finally vascular development and cell division were affected by auxin. Thus it was concluded from our data that vascular bundles distribution and cells division might affect the bulged surface of pear fruits. This study will provide theoretical basis for the regulation of bulged surface of pear fruits by growth retardant agent (Fig. 6).

\section{Conclusions}

PBZ regulated the growth and development of vascular bundles related genes and cell division by negatively regulating auxin signal pathway and retarding strong cell growth vigor, which affected the cell 
division, cell elongation and vascular bundle development on bulged surface of pear fruits, thus relieving the bulged surface in pear fruits.

\section{Methods}

\section{Source of plants}

A Chinese pear fruits variety 'Yuluxiangli' was used from Pomology Institute, Shanxi Academy of Agricultural Sciences, Taigu of China. Paclobutrazol (PBZ) plant growth retardant was sprayed at the full blooming stage of 'Yuluxiangli' with a concentration of 1500 times dilution ratio (PK: treated group), and $\mathrm{ddH}_{2} \mathrm{O}$ was sprayed on control group (CK: control group). Random block design (RBD) was used, each treatment was repeated and applied three times. At full blooming stage, after 85 days of plants full blooming the treated young fruits were collected and immediately snap-frozen in liquid nitrogen and stored at $-80{ }^{\circ} \mathrm{C}$ until RNA and DNA extraction. The fruits were immediately treated for hormone detection and tissue morphology observation. Pear genome sequences were downloaded from website(http://gigadb.org)

\section{Auxin hormone determination}

A total of $0.15 \mathrm{~g}$ flesh of young fruit was accurately weighed and were used to determine the content of IAA using a method developed by Trione [55].

\section{Staining Method}

After fruits coloring from the fruit stalk, each fruit was crosscut from the middle to its core with a sharp blade using a method presented by Ma [56].

\section{Paraffin wax section}

Each fruit was cut perpendicularly from the pericarp to the core of the fruits with a sharp blade. Further, excised three long fruit tissues with a cross-section size of $3 \mathrm{~mm} \times 3 \mathrm{~mm}$. Immediately were fixed for no more than $24 \mathrm{~h}$ with Carnot fixation solution of FAA ( $5 \%$ formaldehyde: $5 \%$ acetic acid: $50 \%$ ethanol). Subsequently dehydrated by washing with a series of ethanol, cleaned by dipping in dimethylbenzene and packed in paraffin. Finally portioning was performed by microtome. Portioned samples were stained with safranin and fast green. Olympus biological microscope (IX81, Tokyo, Japan) was used for sample observation. The length of cells were calculated according to the scale of the light microscope. However, the number of cells and its layers were calculated at the same time. Paraffin sections were prepared a method developed by Yang [57] and Chen [3].

\section{RNA extraction and RNA-seq data analysis}

A total of $0.1 \mathrm{~g}$ flesh of fruits were placed in a precooled mortar with liquid nitrogen. The improved CTAB method was used to extract RNA from the flesh fruits following the manufacturer's instructions. Extracted RNA was dissolved in nuclease-free water and their quality and integrity were measured by 
NanoPhotometer ${ }^{\circledR}$ spectrophotometer (IMPLEN, CA, USA) and 1\% agarose gel electrophoresis, respectively. The RNA concentration was estimated using a Qubit ${ }^{\circledR}$ RNA Assay Kit in Qubit@2.0 Flurometer (Life Technologies, CA, USA). Following RNA isolation and quality assessment, cDNA libraries were constructed and remaining nucleic acids was used for transcript analysis. An equal amount (500 ng) of total RNA was pooled from the biological replicates from each sample for each cDNA library construction. The libraries were sequenced using an Illumina Hiseq4000 platform. The above protocol steps developed by Zhang were followed[23]. The sequencing of raw data was deposited inRNA-seq data, GO and KEGG analysis were performed using BMKCloud (www.biocloud.net) online tool. Genes with an adjusted $p$-value $<0.05$ ( $\mid$ log2(fold change) $\mid \geq 1$ ) found by DESeq were considered as DEGs. Gene expression pattern analysis were carried out by BMKCloud (https://www.biocloud.net/) online tool.

\section{Quantitative RT-PCR analysis}

A total of $500 \mathrm{ng}$ amount of RNA was used to synthesize first-strand cDNA, using TUREscript 1st-Stand cDNA SYNTHESIS Kit (Aidlab Biotechnologies Co., Ltd, China) as templates, following the manufacturer's protocol. The diluted cDNA was used as a template and Real Time PCR Detection System was carried out by Analytikjena-qTOWER2.2 system (Germany). The detailed procedure and primers were listed in Additional file files (Additional file Table S7). The Tublin gene (Tubulin-F: TGGGCTTTGCTCCTCTTAC; Tubulin-R: CCTTCGTGCTCATCTTACC) was used as a reference primer [58]. Three biological replicates were carried out for each sample. The qRT-PCR data were analyzed by the $2^{-\Delta \Delta C t}$ quantitative method to determine the differences. The expression data of these genes were transformed in log2 (Change Fold) values and used for heat map generation.

\section{Cis-element analysis in promoter regions}

To perform cis-element analysis, 1-1.5 kb of genomic DNA sequences upstream of each genes initiation codon (ATG) were downloaded, and then were detected by PlantCARE database (http://www.dna.affrc.go.jp/PLACE/) [60].

\section{Statistics of analysis}

The number of vascular bundles at different treatments were calculated at the size of $10 \mathrm{~mm} \times 10 \mathrm{~mm}$ and cell layer was at the width of $400 \mu \mathrm{m} \times 400 \mu \mathrm{m}$, respectively. The cell numbers were calculated at the size of $100 \mu \mathrm{m} \times 100 \mu \mathrm{m}$ at 15 visual fields. Data of Analysis of variance (ANOVA) was performed and multiple comparisons of the means were conducted by the student test at a $\mathrm{P}$ value $<0.05$.

\section{Abbreviations}

IAA: Auxin; GH3 Gretchen hagen3;KEGG: Kyoto Encyclopedia of Genes and Genomes;PBZ:

Paclobutrazol;PK: Paclobutrazol treatment; $\mathrm{CK}$ : $\mathrm{ddH}_{2} \mathrm{O}$ treanment;DEGs: Differentially expressed genes; PIN: pin-formed 1; AUX: auxin influx carrier; COMT: Caffeic acid 3-0-methyltransferase;4CL: 4-coumarateCoA ligase 1; CYP73A2: Cytochrome P450 73A2;CSE: Caffeoyl shikimate esterase; NAC: domaincontaining protein 2; DOF4.6: Dof zinc finger protein; CesA: Cellulose synthase $A$ 


\section{Declarations}

\section{Ethics approval and consent to participate}

This article did not include any experiments with human participants or animals performed by all the authors.

\section{Consent for publication}

Not applicable.

\section{Availability of data and materials}

The datasets used and analyzed during the above research are available from the Additional file or corresponding author.The pear genome datasets used during the current study are available in the website(http://gigadb.org). The RNA-seq data were deposited in NCBI bioproject (https://www.ncbi.nlm.nih.gov/bioproject/) under accession number PRJNA627328 and in BMKCloud platform (https: //international.biocloud.net/zh/mydata/private/05889c21-f545-4119-ab38b87c64ea925c).

\section{Competing interests}

The authors declare that they have no competing interests.

\section{Funding}

This work was supported in part by grants from the National Key R\&D Program of China (2018YFD0201407) and Excellent PhD Reward Project Fund of Shanxi Province (SXYBKY201736). These fundings provided the financial support to the research projects, but did not contain project design, data collection,analysis, or preparation of the manuscript.

\section{Author Contributions}

LL planned and designed the research. BD collected the plant materials, performed the experiment, analyzed the data, interpreted results, and wrote the manuscript. $\mathrm{CH}$ and TC contributed to sample data collection. YS analyzed the part of data. RH and XF provided suggestions in drafting the manuscript and edited the manuscript. All authors have read and approved the final manuscript.

Acknowledgments: We would like to thank researcher Huangping Guo (Pomology Institute, Shanxi Academy of Agricultural Sciences, Taiyuan 030031, China) and Yuanyuan Chen (Institute of Farm Product Storage and Fresh-keeping, Shanxi Academy of Agriculture Sciences, Taiyuan 030031, China) for their materials; We thanked professor Yuanhui Han (College of Agriculture, Shanxi Agricultural University, Taigu 030801, Shanxi, China) for his kind suggestions to the manuscript. Finally, we thanked engineers from BMKCloud platform for their bioinformatic software. 


\section{References}

1. Wu J, Wang YT, Xu JB, Korban SS, Fei ZJ, Tao ST, Ming R, Tai SS, Khan AK, Postman JD, Gu C, Yin H, Zheng DM, Qi KJ, Li Y, Wang RZ, Deng CH, Kumar S, Chagné D, Li XL, Wu JY, Huang XS, Zhang HP, Xie ZH, Li X, Zhang MY, Li YH, Yue Z, Fang XF, Li JM, Li LT, Jin C, Qin MF, Zhang JY, Wu X, Ke YQ, Wang J, Yang HM, Zhang SL. Diversification and independent domestication of Asian and European pears. Genome Biol. 2018, 19(1)

2. Teng YW. Advances in the research on phylogeny of the genus Pyrus and the origin of pear cultivars native to East Asia. J Fruit Sci. 2017; 34(03):370-

3. Chen YY, Li K, Song YQ, Li N, Li LL. Effect of growth regulator PBO on fruit decalyx and quality of pear. South China Fruits. 2018; 47(5):55-58.

4. Koukourikou-Petridou MA. Paclobutrazol affects the extension growth and the levels of endogenous IAA of almond seedlings. Plant Growth Regul. 1996; 18(3):187-190.

5. Burondkar MM, Upreti KK, Ambavane AR, Rajan S, Mahadik SG, Bhave SG. Hormonal changes during flowering in response to paclobutrazol application in mango $\mathrm{cv}$. Alphonso under konkan conditions. Indian J Plant Physiol. 2016; 21(3):306-311.

6. Fang ZG, Zhao XF. Effects of paclobutrazol (PP333) on free endogenous hormones concentration in the leaves of rice and wheat seedling. J Laiyang Agri Col. 2005; 22(2):101-

7. Chen J. Effects of growth regulant on development of calyx and dynamic change of endogenous hormone and fruit quality in Chinese pear 'Dangshansuli'. Anhui Agri Univ.

8. Ma HC, Wang YL, Wen X, Qi M, Li J. Effects of different reagent treatments on the microstructure of calyx tube with or without calyx of Korla fragrant pear. J Fruit Sci. 2011; 28:518-520+551.

9. Ma HY, Tao ST, Chen Y, Yu RR, Chen XY, Bao JP, Wu CY, Zhang R. Study on relationship between vascular bundle and sepal abscission in different orders of inflorescenceson short fruiting branches of Korla fragrant pear. Acta Agri Jiangxi. 2019; 31(04):26-30.

10. Xie ZS, Cao HM, Liu AL, Wang B, Wang SP. The effects of root restriction on water transport in the vascular bundle of grape fruit during different stages of development. Plant Physiol J. 2011; 47(9):899-903.

11. Nii, N. Seasonal changes in growth and enlargement of the Japanese fruit, Pyrus Serotina cv Shinseiki, in relation to vascular bundle development in the pedicel and flesh. J Hort Sci. 1980; 55(4):385-396.

12. Qi HY, Li T, Liu HT, Zhang J. Change in $14 \mathrm{C}$-soluble sugar involved in the photosynthate translocation pathway of tomato. Agri Sci China. 2006; 5(3):209-215.

13. Chen FY, Ni HZ, Wang Y, Ren ZC. Effect of paclobutrazol (PP_333) on growth and fruiting of Dongkui bayberry(Myrica rubra). Asian J Ecotoxicol. 2011; 6(6):661-666. 
14. Zhou WQ, Yang WL, Zhao SL, Man SE, Na SE, Qi YQ, Liao K. Response of leaf tissue structure to $\mathrm{PP}_{333}$ in Korla fragrant pear. Agri Sci Tech. 2017; 18(10):1805-1807+1815.

15. Gälweiler L, Guan C, Müller A, Wisman E, Mendgen K, Yephremov A, Palme K. Regulation of polar auxin transport by AtPIN1 in Arabidopsis vascular tissue. Science. 1998; 282(5397):2226-2230.

16. Scarpella E, Marcos D, Friml J, Berleth Control of leaf vascular patterning by polar auxin transport. Gene Dev. 2006; 20(8):1015-10 27.

17. Wiśniewska J, Xu J, Seifertová D, Brewer PB, Růžička K, Blilou I, Rouquié D, Benková E, Scheres B, Friml J. Polar PIN localization directs auxin flow in plants. Science. 2006; 312(5775):883-883.

18. Péret, B, Swarup, K, Ferguson, A, Seth, M, Yang, Y.D, Dhondt, S, James, N, Casimiro, I, Perry, P, Syed A, Yang HB, Reemmer J, Venison E, Howells C, Perez-Amador MA, Yun J, Alonso J, Beemster GTD, Laplaze L, Murphy A, Bennett BJ, Nielsen E, Swarup R. AUX/LAX genes encode a family of auxin influx transporters that perform distinct functions during Arabidopsis development. Plant Cell. 2012;24(7):2874-2885.

19. Moreno-Piovano GS, Moreno JE, Cabello JV, Arce AL, Otegui ME, Chan RL. A role for LAX2 in regulating xylem development and lateral-vein symmetry in the leaf. Ann Bot. 2017; 120(4):577-590.

20. Besseau S, Hoffmann L, Geoffroy P, Lapierre C, Pollet B, Legrand M. Flavonoid accumulation in Arabidopsis repressed in lignin synthesis affects auxin transport and plant growth. Plant Cell. 2007; 19(1):148-162.

21. Weng JK, Mo H, Chapple C. Over-expression of $F 5 H$ in COMT-deficient Arabidopsis leads to enrichment of an unusual lignin and disruption of pollen wall formation. Plant J. 2010; 64(6):898911.

22. Lin CY, Wang JP, Li Q, Chen HC, Liu J, Loziuk P, Song J, Williams C, Muddiman DC, Sederoff RR, Chiang VL. 4-coumaroyl and caffeoyl shikimic acids inhibit 4-coumaric acid: coenzyme a ligases and modulate metabolic flux for 3-hydroxylation in monolignol biosynthesis of Populus trichocarpa. Mol Plant. 2015;8(1):176-187.

23. Zhang X, Zhang LJ, Zhang QP, Xu JY, Liu WS, Dong WX. Comparative transcriptome profiling and morphology provide insights into endocarp cleaving of apricot cultivar ( Prunus armeniaca). BMC Plant Biol. 2017; 17:72.

24. De Rybel B, Möller B, Yoshida S; Grabowicz I, Barbier de Reuille P, Boeren S, Smith RS, Borst JW, Weijers D A. bHLH complex controls embryonic vascular tissue establishment and indeterminate growth in Arabidopsis. Dev Cell. 2013; 24(4):426-437.

25. Ohashi-ito K, Oguchi M, Kojima M, Sakakibara H, Fukuda H. Auxin-associated initiation of vascular cell differentiation by LONESOME HIGHWAY. Development 2013. 140(4):765-769.

26. Zhang YX, Han XJ, Sang J, He XL, Liu MY, Qiao GR, Zhuo RY, He GP, Hu JJ. Transcriptome analysis of immature xylem in the Chinese fir at different developmental phases. Peer J. 2016; 4(17):e2097.

27. Yamaguchi $M$, Mitsuda N, Ohtani M, Ohme-takagi M, Demura T. VASCULAR-RELATED NAC-DOMAIN 7 directly regulates the expression of a broad range of genes for xylem vessel formation. Plant J. 2011; 66(4):579-590. 
28. Zhong RQ, Ye ZH. Complexity of the transcriptional network controlling secondary wall biosynthesis. Plant Sci. 2014; 229:193-207.

29. Hao GW, Bai MD, Gao P, Yang S, Guo HP. Effect of growth regulator on decalyx rate and fruit quality of pear. Shanxi Fruits. 2016; 5(4): 15-18.

30. Xue GX, Wu XY, Wang Y, Fan Effect of GA and $\mathrm{PP}_{333}$ on longitudinal diametre and diametre of applepear. J Agri Sci Yanbian Univ. 1999; 2(4):95-97.

31. Ma CL, Chen SY, Liu XH. Effects of PP 333 on tissue structure in leaves, cold resistance and growth of shoots of pummelo trees. Fujian J Agri Sci. 2000; 15(1):26-29.

32. Qin GX, Zhang GQ, Zhai QX, Zhang Y, Wang YJ. Effect of $\mathrm{PP}_{333}$ on the cell anatomy structure of the secondary xylem of greenhouse cultivated grape. J fruit sci. 2004; 21(5):480-481.

33. Su L, Bassa C, Audran C, Mila I, Cheniclet C, Chevalier C, Bouzayen M, Roustan J, Chervin C. The auxin SI-IAA17 transcriptional repressor controls fruit size via the regulation of endoreduplicationrelated cell expansion. Plant Cell Physiol. 2014; 55(11):1969-1976.

34. Renée G, Roger P, Dubacq JP. In situ and IAA-induced cell elongation is correlated to the oleyl phosphatidylcholine content along the vigna radiata hypocotyl. Plant Cell Physiol. 1983; 24(3):541-549.

35. Blilou I, Xu J, Wildwater M, Willemsen V, Paponov I, Friml J,Heidstra R, Aida M, Palme K, Scheres B. The PIN auxin efflux facilitator network controls growth and patterning in Arabidopsis Nature. 2005; 433(7021):39-44.

36. Bruck DK, Paolillo, DJ. Replacement of leaf primordia with IAA in the induction of vascular differentiation in the stem of colecus. New Phyto 1984; 96(3):353-370.

37. Ma YL, Steeves TA. Auxin effects on vascular differentiation in ostrich fern. Ann Bot. 1992; 70(3):277-282.

38. Groover AT, Pattishall A, Jones AM. IAA 8 expression during vascular cell differentiation. Plant Mol Biol. 2003; 51(3):427-435.

39. Dhonukshe D, Aniento F, Hwang I, Robinson DG, Mravec J, Stierhof YD, Friml Clathrin-mediated constitutive endocytosis of PIN auxin efflux carriers in Arabidopsis. Curr Biol. 2007; 17(6):520-527.

40. Friml, J. Auxin transport-shaping the plant. Curr Opin Plant Biol. 2003; 6(1):7-

41. Wenzel CL, Schuetz M, Yu Q, Mattsson J. Dynamics of MONOPTEROS and PIN-FORMED1 expression during leaf vein pattern formation in Arabidopsis thaliana. Plant J. 2010; 49(3):387-398.

42. Zhang ZY, Li JJ, Tang ZS, Sun XM, Zhang HL,Yu JP, Yao GX, Li GL, Guo HF, Li GL, Wu HM, Huang HG, Xu YW, Yin ZG, Qi YH, Huang RF, Yang WC, Li Gnp4/LAX2, a RAWUL protein, interferes with the OsIAA3-OsARF25 interaction to regulate grain length via the auxin signaling pathway in rice. J Exp Bot. 2018; 69(20):4723-4737

43. Mittag J, Šola I, Rusak G, Ludwig-Müller Physcomitrella patens auxin conjugate synthetase (GH3) double knockout mutants are more resistant to Pythium infection than wild type. J Plant Physiol. 2015; 183:75-83. 
44. Bell-Lelong DA, Cusumano JC, Meyer K, Chapple C. Cinnamate-4-hydroxylase expression in Arabidopsis. Regulation in response to development and the environment. Plant Physiol. 1997; 13(3):729-738.

45. Ohashi-Ito K, Fukuda H. Functional mechanism of bHLH complexes during early vascular development. Curr Opin Plant Biol. 2016; 33:42-47.

46. Katayama H, Iwamoto K, Kariya Y, Asakawa T, Kan T, Fukuda H, Ohashi-Ito K A negative feedback loop controlling bHLH complexes is involved in vascular cell division and differentiation in the root apical meristem. Curr biol:CB. 2015; 25(23):3144-3150.

47. Ohashi-Ito K, Oda Y, Fukuda H. Arabidopsis VASCULAR-RELATED NAC-DOMAIN6 directly regulates the genes that govern programmed cell death and secondary wall formation during xylem differentiation. Plant Cell. 2010, 22(10):3461-3473.

48. Yamaguchi M, Goué N, Igarashi H, Ohtani M, Nakano Y, Mortimer JC, Nishikubo N, Kubo M, Katayama Y, Kakegawa K, Dupree P, Demura T. VASCULAR-RELATED NAC-DOMAIN 6 and VASCULARRELATED NAC-DOMAIN7 effectively induce transdifferentiation into xylem vessel elements under control of an induction system. Plant Physiol. 2010; 153(3):906-914.

49. Yamaguchi M, Ohtani M, Mitsuda N, Kubo M, Ohme-Takagi M, Fukuda H, Demura T. VNDINTERACTING2, a NAC domain transcription factor, negatively regulates xylem vessel formation in Arabidopsis. Plant Cell. 2010; 22(4):1249-1263.

50. Zhong RQ, Ye ZH. MYB46 and MYB83 bind to the SMRE sites and directly activate a suite of transcription factors and secondary wall biosynthetic genes. Plant Cell Physiol. 2012; 53(2):368-380.

51. Zhong RQ, Morrison H, Freshour GD, Hahn, MG, Ye ZH. Expression of a mutant form of cellulose synthase AtCesA7 causes dominant negative effect on cellulose biosynthesis. Plant Physiol. 2003; 132(2):786-795.

52. Nairn CJ, Haselkorn T. Three loblolly pine CesA genes expressed in developing xylem are orthologous to secondary cell wall CesA genes of angiosperms. New Phytol. 2005; 166(3):907-915.

53. Hu WJ, Kawaoka A, Tsai CJ, Lung J, Osakabe K, Ebinuma H, Chiang VL. Compartmentalized expression of two structurally and functionally distinct 4-coumarate: CoA ligase genes in aspen (Populus tremuloides). Proc Natl Acad Sci USA. 1998, 95(9):5407-5412.

54. Yang J, Chen F, Yu O, Beachy RN. Controlled silencing of 4-coumarate:CoA ligase alters lignocellulose composition without affecting stem growth. Plant Physio Bioch. 2010; 49(1):103-109.

55. Trione EJ, Krygier BB, Kathrein JM, Banowetz GM, Sayavedra-soto LA. Monoclonal antibodies against the plant cytokinin isopentenyl adenosine. Physiol Plantarum. 1987; 70(3):467-472.

56. Ma XH. Making transparent vascular bundle skillfully by dyeing. Bul Biol. 1996; 31(12):

57. Yang L, Qin ZQ, Wu T, Li XM, Tu JF, Yang FC, Zhu HY, Liu Z. Paraffin section preparation of pear fresh tissue at different development stages. Bul Agril Sci Tech. 2017; 12:213-215.

58. Qi XX, Wu J, Wang LF, Li LT, Cao YF, Tian LM, Dong XG, Zhang SL. Identifying the candidate genes involved in the calyx abscission process of 'kuerlexiangli' (Pyrus Sinkiangensis Yu) by digital transcript abundance measurements. BMC Genomics. 2013; 14:727- 
59. Livak KJ, Schmittgen TD. Analysis of relative gene expression data using Real-Time Quantitative PCR and the $2^{-\triangle \triangle}$ Ct method . Methods. 2001; 25(4):402-408.

60. Lescot M, Déhais P, Thijs G, Marchal K, Moreau Y, Van de Peer Y, Rouzé P, Rombauts S. PlantCARE, a database of plant cis-acting regulatory elements and a portal to tools for in silico analysis of promoter sequences. Nucleic Acids Res. 2002; 30(1):325-327.

\section{Supplementary Materials}

Additional file 1: Fig. S1. Graph of bulged surface of pear fruits at different development stage.The bulged surface of pear fruits at the early, middle and late stage of fruits.

Additional file 2: Fig. S2. Differentially expressed vol diagram. The $Y$ axis shows the log2 FPKM values, FPKM (Fragments Per Kilobase of exon model per Million mapped reads) values, $X$ axis shows log2 fold change.Red, green and black indicate up, down and unchanged expression, respectively (Fold change $\geq 1$, $p$-value $<0.05$ )

Additional file 3: Table S1. Statistics of differentially expressed genes in response to PBZ.

Additional file 4: Table S2. The number of differential expression annotated genes in database.

Additional file 5: Table S3. The list of differentially expressed genes.

Additional file 6: Table S4. The list genes of GO enrichment.

Additional file 7: Table S5. The list of genes enriched on KEGG pathway

Additional file 8: Table S6. Identification genes involved in bulged surface of pear fruits

Additional file 9: Table S7 Primers used to perform qRT-PCR of selected candidate genes.

Additional file 10: Table S8. Quantitative RT-PCR method.

\section{Figures}



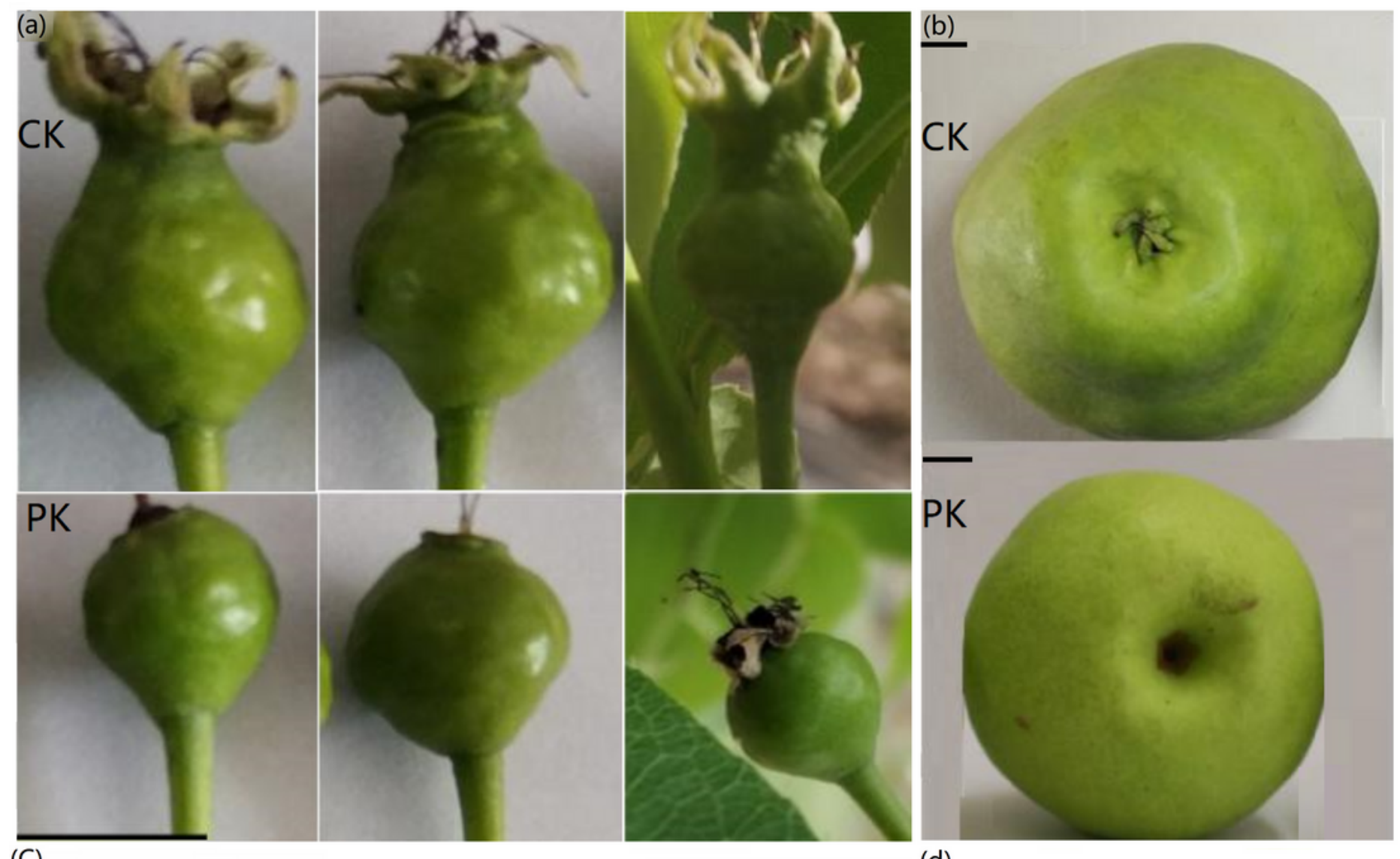

(C)

(d)
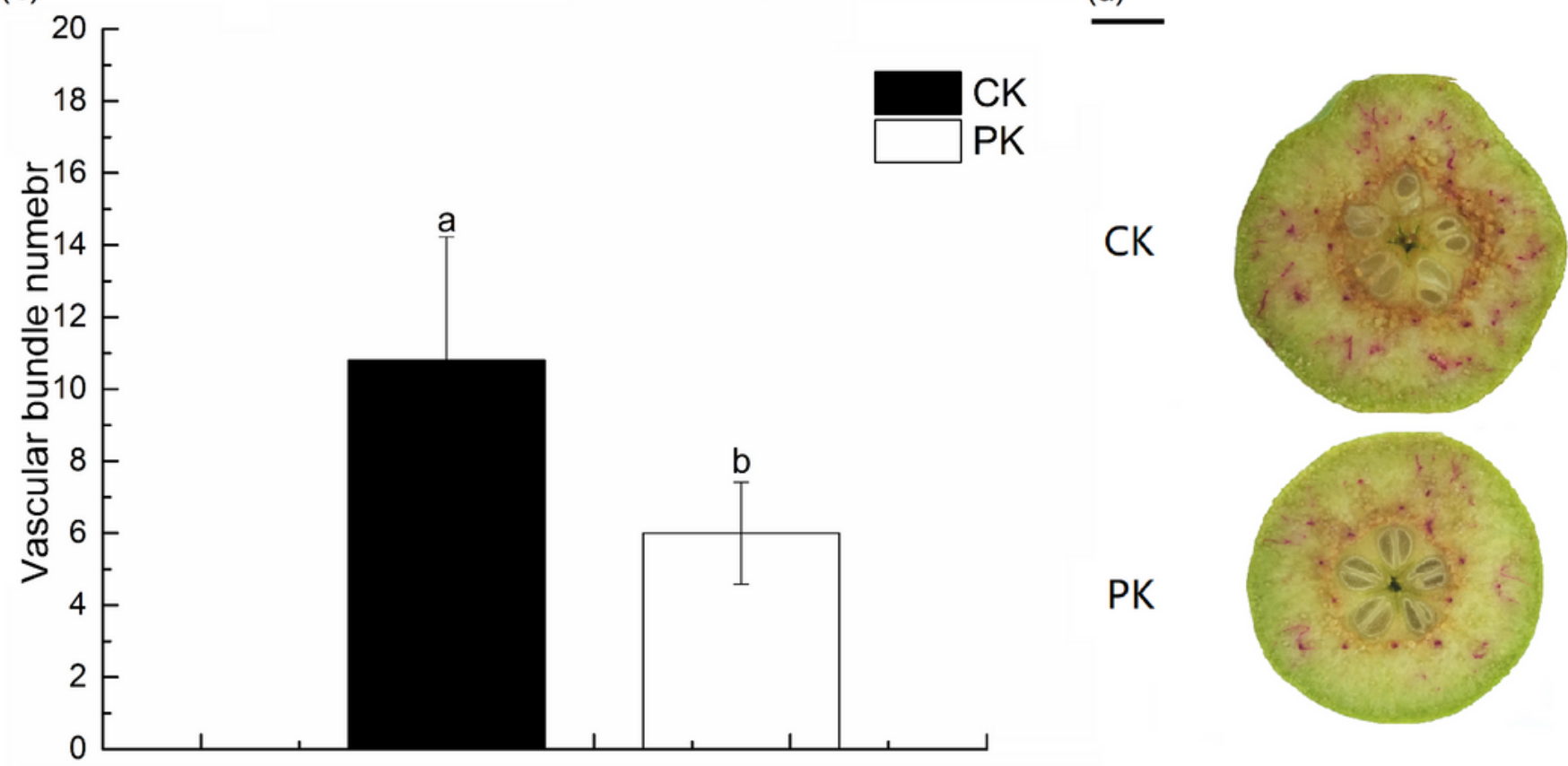

\section{Figure 1}

The bulged surface of pear fruits and schematic diagram of vascular bundles in CK and PK groups. (a) The bulged surface of pear fruits at the stage of young fruits. (b) The bulged surface of pear fruits at the stage of mature fruits. (c) Statistic number of vascular bundles. CK indicates control group treated by ddH2O, PK indicates PBZ treatment. Scale bar $=10 \mathrm{~mm}$. (d) The cross section of pear fruits. Student t-test $(p<0.05)(n=15 \pm S E)$. 


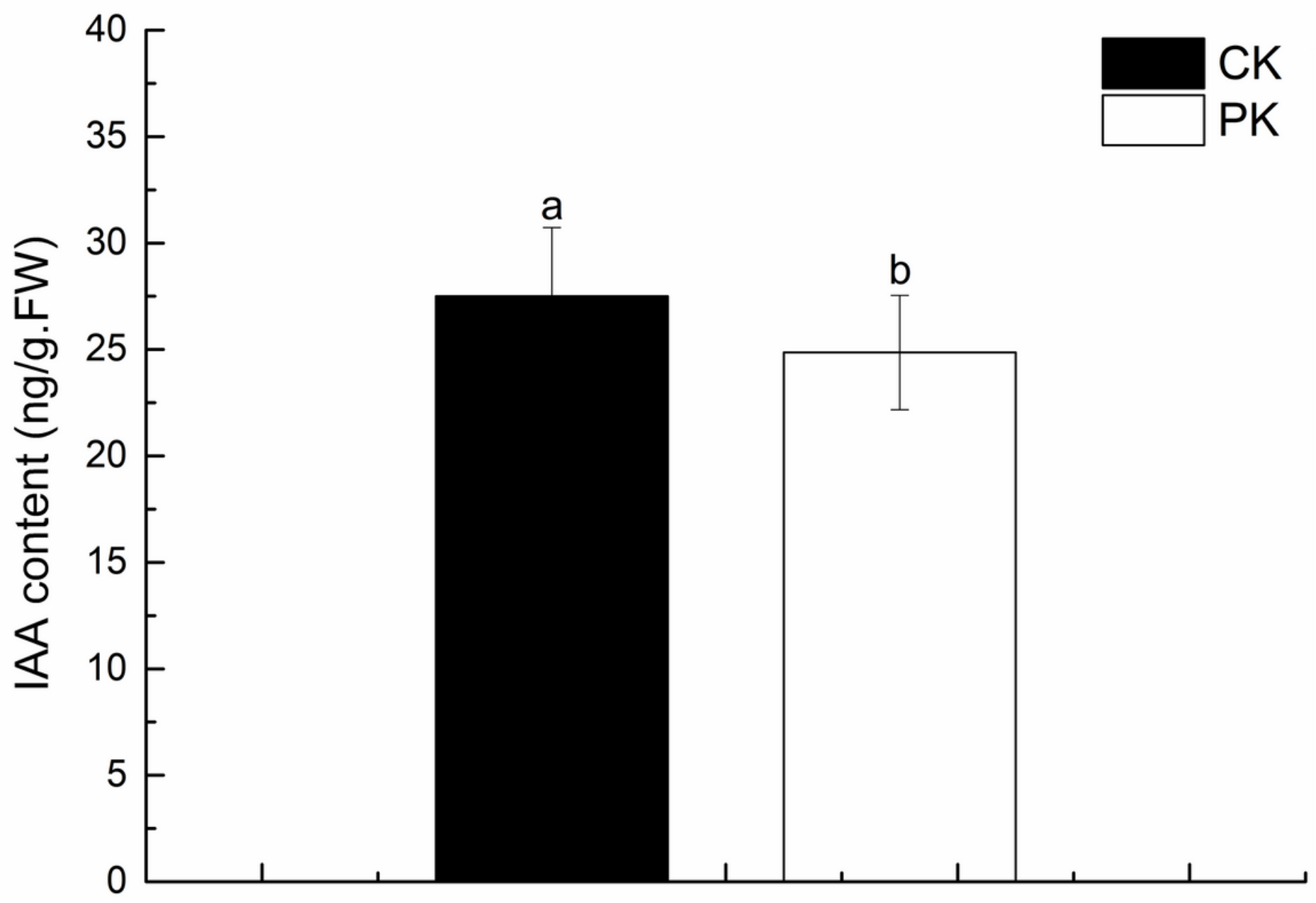

Figure 2

The IAA content of measurement analysis in CK and PK groups. Error bars represent standard deviation of three biological replications, student t-test $(p<0.05)$. 
(a)

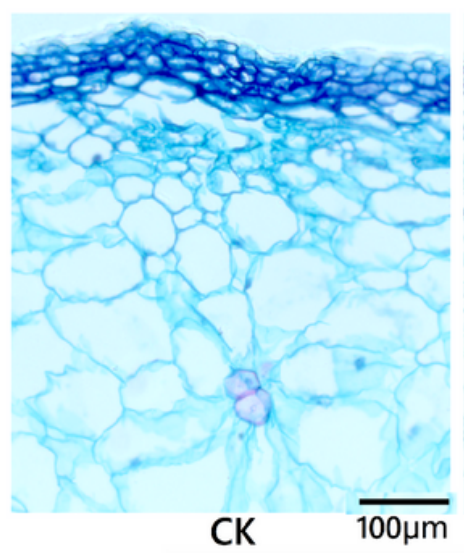

(c)
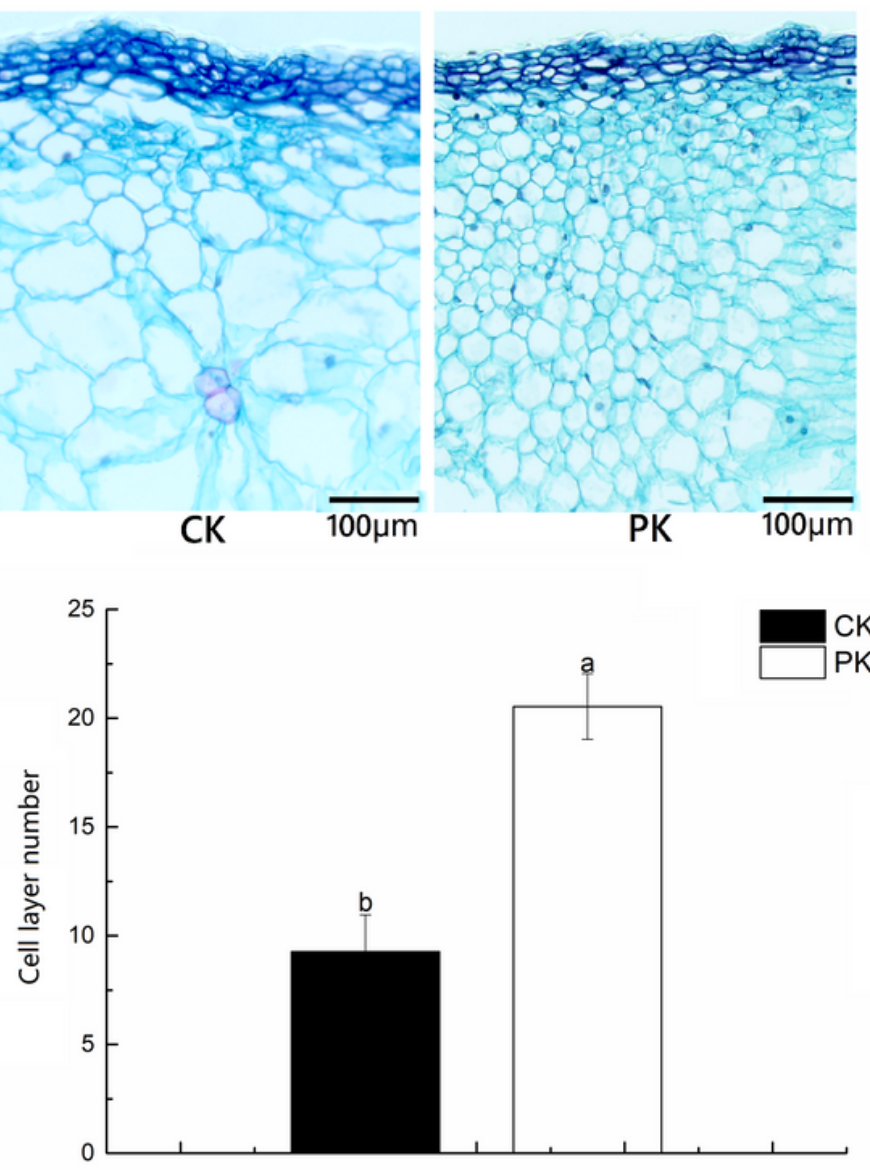

(b)
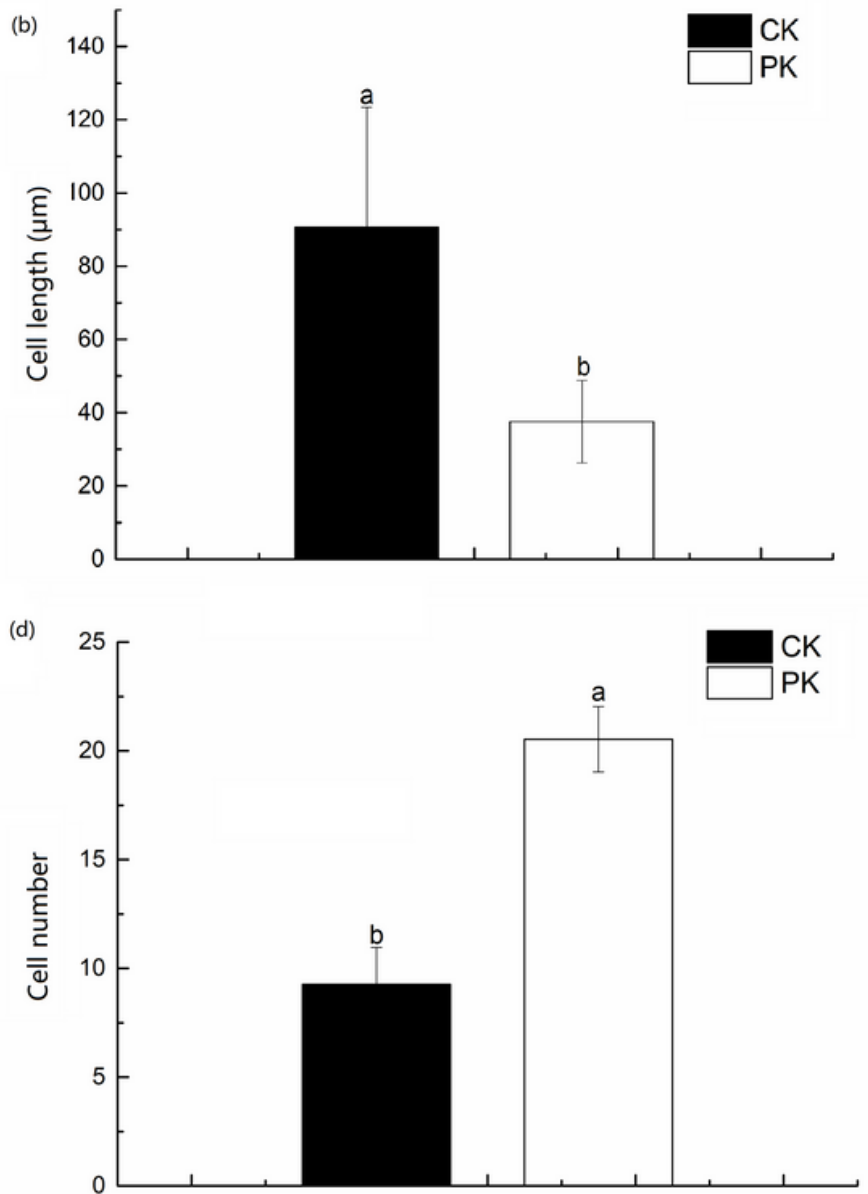

Figure 3

Structure and statistic of pear fruits in CK and PK groups. (a) Structure of pear fruits. Scale bar $=100 \mu \mathrm{m}$. (b) The length of fruit cells . (c) The number of cell layers. Cell layers were at the size of $400 \mu \mathrm{m} \times 400 \mu \mathrm{m}$. (d) The number of fruit cells. Cell numbers were at the size of $100 \mu \mathrm{m} \times 100 \mu \mathrm{m}$. Letter indicated statistical difference between CK and PK by student t-test $(p<0.05)(n=15 \pm$ SE). 


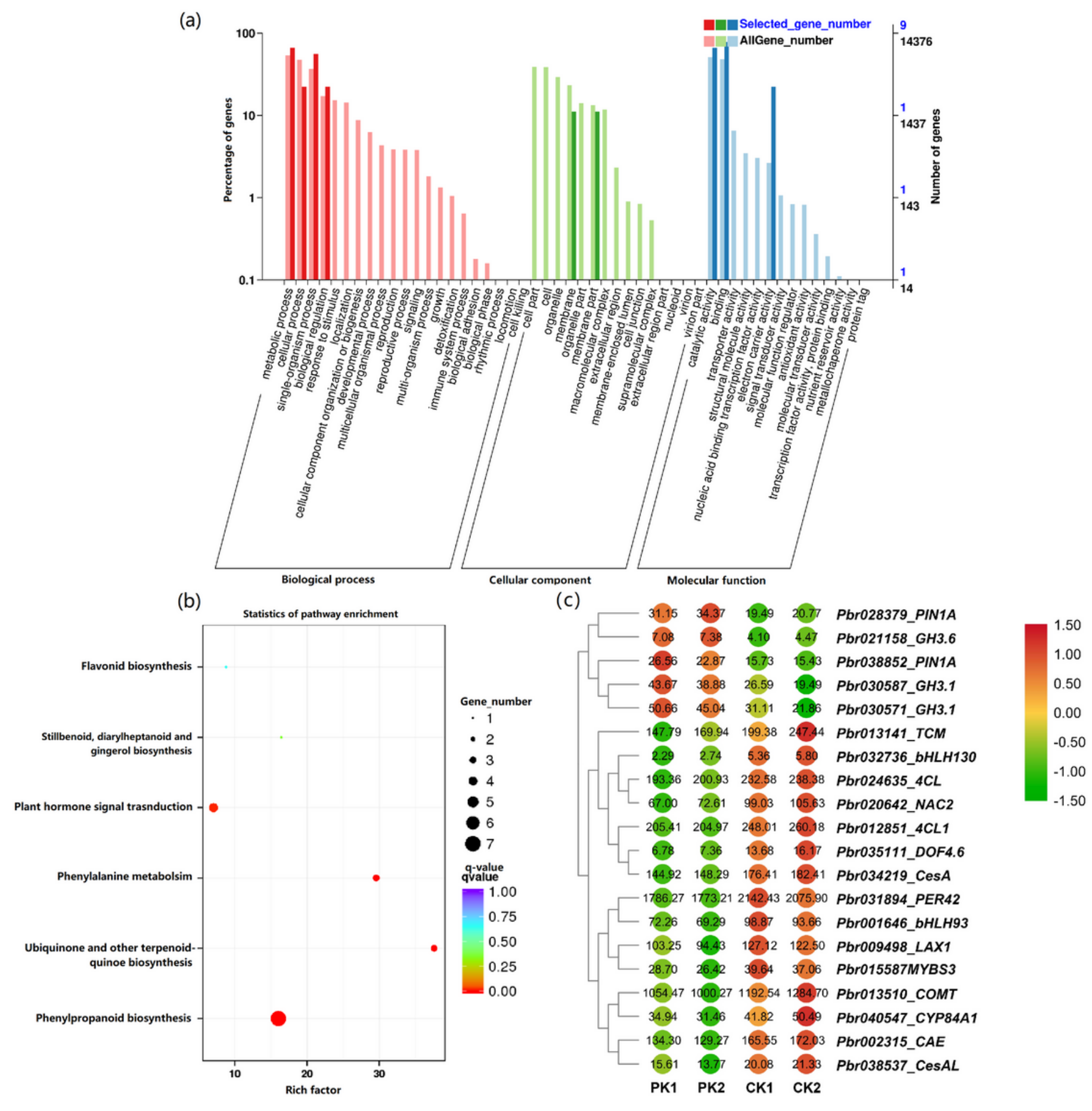

Figure 4

DEGs of cluster analysis and enrichment on GO and KEGG. (a) Gene Ontology (GO) enrichment of DEGs. (b) KEGG enrichment of selected DEGs. X-axis represents the enrichment factor (rich factor) which is the ratio of the foreground value (the number of DEGs) and the background value (total gene amount). The Yaxis shows the pathway names. (c) Heatmap depicting relative expression profile. 


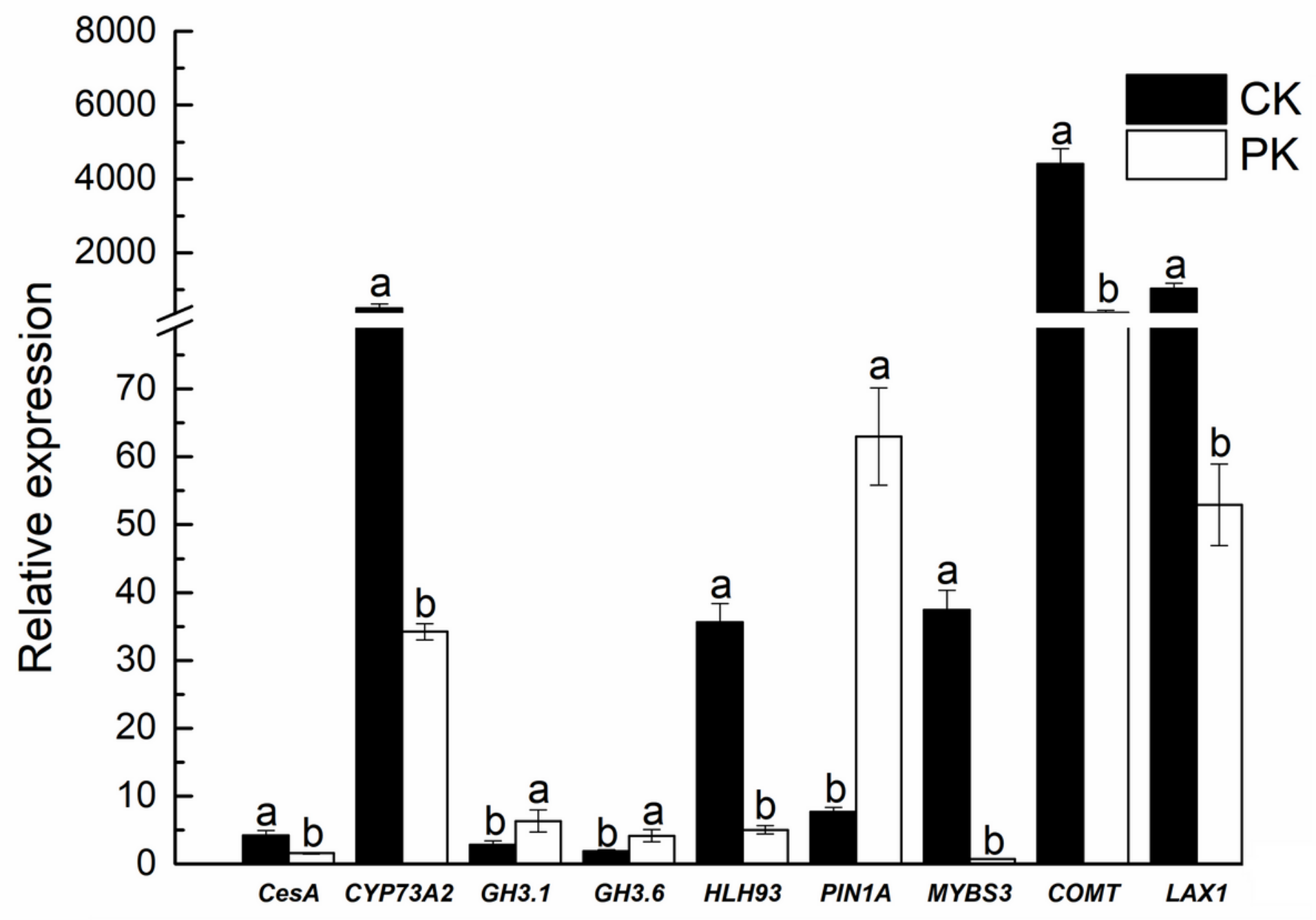

Figure 5

qRT-PCR expression profile of candidate DEGs in RNA-seq data in CK and PK groups. The error bars with different letters $(a b)$ denote significant differences in CK and PK groups and mean \pm SD (standard deviation, $n=3, p<0.05)$. 


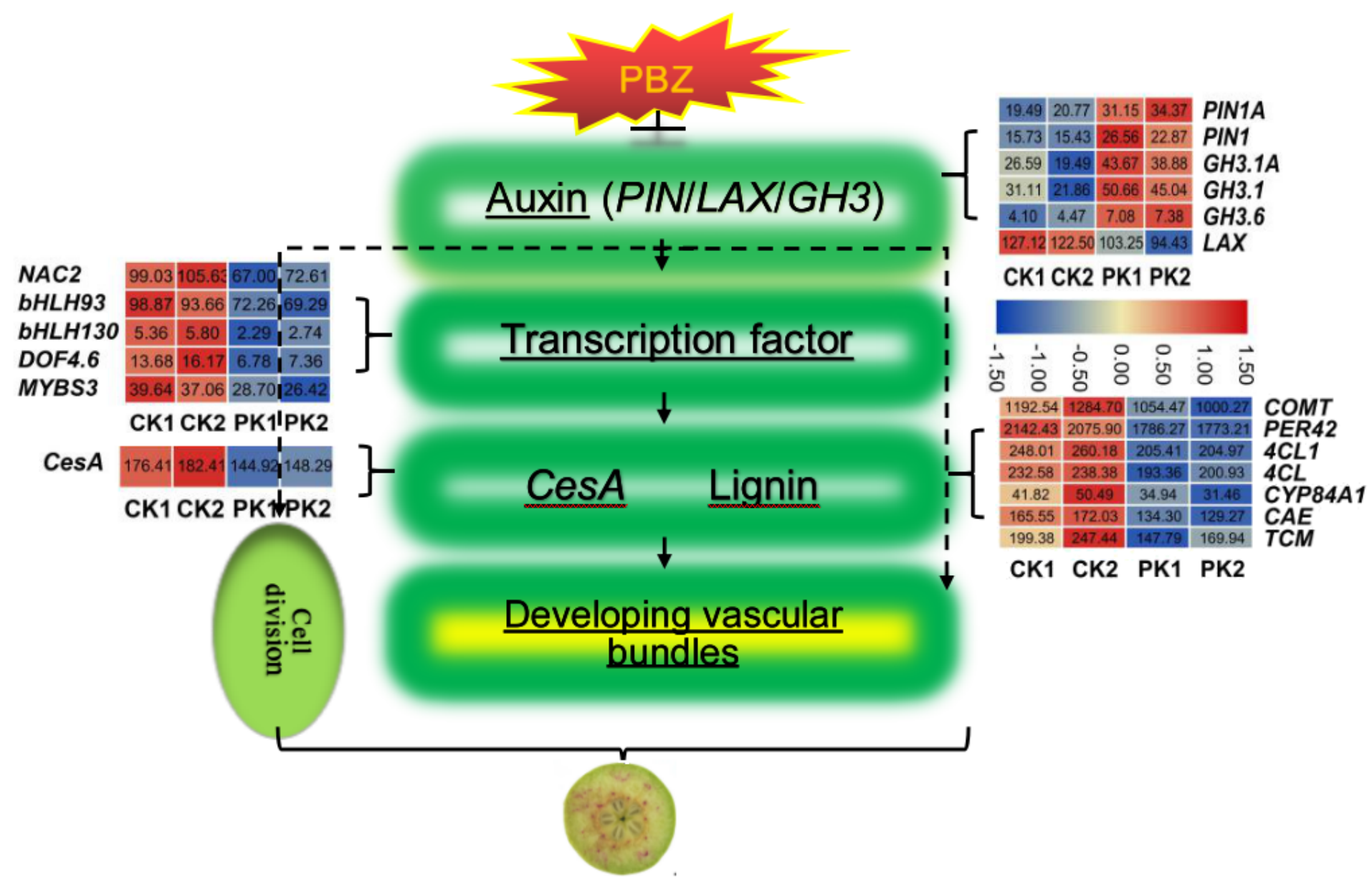

Figure 6

A hypothetical representation of regulatory network in relieved pear-bulged surface fruits treated by PBZ. Black dotted line with arrows denote indirectly positive regulation, whereas black solid line means directly positive regulation. black solid with blunt ends denotes negative regulation.

\section{Supplementary Files}

This is a list of supplementary files associated with this preprint. Click to download.

- AdditionalfileTableS6.xIsx

- AdditionalfileTables1.xlsx

- AdditionalfileTables2.xlsx

- AdditionalfileFigures1.tif

- AdditionalfileTables3.xlsx

- AdditionalfileFigures2.pdf

- AdditionalfileTables8.xlsx

- AdditionalfileTables4.xlsx 
- AdditionalfileTableS7.xIsx

- AdditionalfileTables5.xIsx 